\title{
European Landscapes in Transition
}

Implications for policy and practice

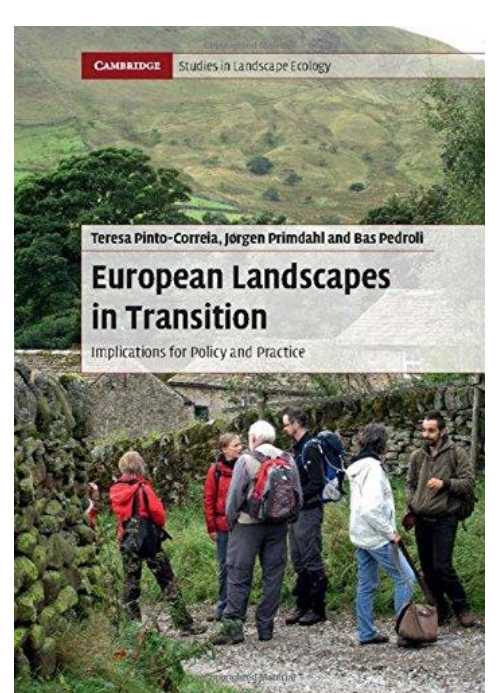

Teresa Pinto-Correia, Universidade de Évora,

Portugal , Jørgen Primdahl, University of Copenhagen, Bas

Pedroli, Wageningen Universiteit, The Netherlands

European rural landscapes as we experience them today are the result of ongoing processes and interactions between nature and society. These are changing fast: the future landscapes will be different from those we know currently. Written for academics, policy-makers and practitioners, this book is the first to explore the complex histories of rural landscapes in Europe as a basis for their sound governance in future. Tensions between the needs of agricultural spaces driven by economic incentives and a variety of non-agricultural functions are explored to demonstrate current challenges and the shortfalls in the policies that address them. Using inspiring case studies that highlight the roles of regional agents and communities, the authors go further than the usual analyses to illustrate the importance of local context. Written by experts currently working to revitalise the rural landscapes of Europe, the text concludes with suggestions for improving landscape policy and planning practice.

\section{Content}

- Introduction: Landscape in Disequilibrium

- What is the rural landscape about?

- Conceptualizing Rural Landscape Change

- Evolving activities in the Rural

- Changing relationships between the rural and the city

- Landscape policy and planning - managing conflicts and making places

- Common Grounds for colorful futures

Pinto-Correia T., Primdahl J., Pedroli B., 2018. European Landscapes in Transition - Implications for Policy and Practice. Cambridge University Press

Publisher: Cambridge University Press

Online publication date: January 2018

Print publication year: 2018

Online ISBN: 9781107707566

https://doi.org/10.1017/9781107707566 